\title{
Toxicity evaluation of single and mixed antifouling biocides measured with acute toxicity bioassays
}

\author{
A.R. Fernández-Alba ${ }^{a, *}$, M.D. Hernando ${ }^{a}$, L. Piedra $^{a}$, Y. Chisti $^{b}$ \\ a Department of Analytical Chemistry, University of Almería, 04120 Almería, Spain \\ ${ }^{\mathrm{b}}$ Institute of Technology and Engineering, Massey University, Private Bag 11 222, Palmerston North, New Zealand
}

Received 24 September 2001; received in revised form 17 December 2001; accepted 10 January 2002

\begin{abstract}
Antifouling biocides used in boat paints were analyzed with a battery of toxicity bioassays to evaluate the toxic effects of these compounds on Vibrio fischeri, Daphnia magna and Selenastrum capricornotum. The antifoulants tested were Irgarol 1051, Kathon 5287, chlorothalonil, diuron, dichlofluanid, 2-thiocyanomethylthiobenzothiazole (TCMTB) and tributyltin (TBT). In most cases, the sensitivity of the organisms towards the toxicants followed the order: S. capricornotum $>$ D. magna $>$ V. fischeri. Toxicity by concentration level had the following order: TBT $=$ Kathon $5287>$ chlorothalonil $>$ Irgarol $1051>$ diuron $>$ dichlofluanid $>$ TCMTB for S. capricornotum. For D. magna ( $48 \mathrm{~h}$ test), the toxicity order of compounds was TBT $>$ Kathon $5287>$ chlorothalonil $>$ TCMTB $>$ dichlofluanid $>$ Irgarol $1051>$ diuron. For V. fischeri $(30$ min test), the compound toxicity had the following order: Kathon $5287>$ TBT $>$ TCMTB $>$ dichlofluanid $>$ Irgarol $1051>$ chlorothalonil.

Degradation products of Irgarol 1051 and diuron were also tested. Degradation product of Irgarol 1051 was found to be less toxic to the crustacean and the microalga but more toxic to the bacterium. Degradation products of diuron were less toxic to the microalga in comparison with the bacterium. For mixtures of compound, toxicities were additive in only 33\% of the cases and $21 \%$ of mixtures were less toxic than expected based on the sum of concentrations of toxicants (antagonistic effect). Synergistic enhancements of toxicity were observed for a majority (46\%) of the mixtures.

The average reproducibility of the $\mathrm{EC}_{50}$ and LOEC measurements was 27,24 and $28 \%$, respectively, in the V. fischeri, S. capricornotum and D. magna bioassays. For single compound, the reproducibility of $\mathrm{EC}_{50}$ was better than $\pm 20 \%$ for a vast majority of the measurements with the V. fischeri system, thus agreeing closely with the reported reproducibility values for this relatively well-known assay. () 2002 Elsevier Science B.V. All rights reserved.
\end{abstract}

Keywords: Antifouling biocides; Toxicity; Daphnia magna; Selenastrum capricornotum; Vibrio fischeri

\section{Introduction}

Antifouling paints are used for controlling growth of marine organisms on submerged structures, such as the hulls of watercraft. Antifouling chemicals are especially important to the shipping industry because biofouling of ships' hulls leads to increased friction

\footnotetext{
* Corresponding author.

E-mail address: amadeo@ual.es (A.R. Fernández-Alba).
}

and fuel consumption, increased cleaning costs and increased time out of service. A $1 \mathrm{~mm}$ thick layer of algal slime will increase hull friction by $80 \%$ and the fuel consumption by $17 \%$ [1].

Until recently, tributyltin (TBT) was one of the most commonly used antifouling agents but this compound is highly toxic to aquatic organisms. TBT bioaccumulates with an accumulation factor as high as 10,000 [2]. Also, TBT is chronically and acutely toxic. TBTs half-life in aerobic and anaerobic conditions ranges 
from 6 to 9 months and its degradation products are also toxic and persistent. In view of these factors, the use of TBT has been restricted in the EU since the late 1980s and biocides with a reduced environmental impact are being introduced. Some of the TBTs replacements used as active ingredients in many antifouling paints include chlorothalonil, dichlofluanid, Kathon 5287 (Sea nine 211), Irgarol 1051, diuron and 2-thiocyanomethylthiobenzothiazole (TCMTB). Irgarol 1051 and diuron are mainly algaecidal and inhibit the photosystem-II (PSII) of the photosynthetic apparatus [3]. Chlorothalonil and dichlofluanid are also used as fungicides in agriculture and act against a wide range of organisms [4,5]. Kathon 5287 is toxic to bacteria, diatoms, algae and barnacles [2] but its chronic or reproductive toxicity to marine species is lower than TBTs [2]. Although effective antifoulants, many of these compounds can cause significant environmental problems as a consequence of their broad toxicity. High concentrations of antifouling agents have been detected in European estuarine and coastal areas, especially in enclosed and semi-enclosed marinas [6-9]. Specific antifoulants in the environment have been identified by analytical methodologies, such as GC-MS, enzyme-linked immunosorbent assay and LC-MS [10-14].

This work reports on toxicity of several organic antifoulants towards aquatic biota. Toxicities of compounds were measured singly and in mixtures of various complexities, using acute toxicity bioassays. As different toxicants act differently and not all life-forms are equally susceptible, several bioassays were used to assess toxicity [15]. We also evaluated the acute toxicity of 2-methylthio-4-tert-butylamino-6-amino-s-triazine, 1-(3,4-dichlorophenyl) methylurea and 1-(3,4-dichlorophenyl) urea, which are some of the degradation products of Irgarol 1051 and diuron. The latter two compounds are the most widely used replacement antifoulants of TBT in the Mediterranean region. The different compositions of the antifouling paints use different biocides and as a consequence, the receiving ecosystem is invariably contaminated with multiple biocides. The combined toxic effects of multiple chemicals have been recognized as an important consideration in ecotoxicology because mixtures of chemicals can have a greater negative impact than the individual constituents of the mixture. Therefore, another objec- tive of this research was to assess the toxic effects of mixtures of antifouling agents.

In summary, this work reports on measured toxicities of several antifoulants, mixtures of antifoulants and the degradation products of some antifoulants. Multiple bioassay systems are used to asses the toxic response. The assay systems used are representative of the organisms encountered in the early stages of aquatic food chains.

\section{Materials and methods}

\subsection{Test chemicals}

Seven antifouling agents and the degradation products of two antifoulants were tested for toxicity. The specific compounds used were Irgarol 1051 (2-methylthio-4-tert-butylamino-6-cyclopropylamino$s$-triazine), Kathon 5287 (4,5-dichloro-2-(n-octyl)-3 (2H)-isothiazolone), dichlofluanid ( $N$-dimethyl- $N$ phenylsulphamide), chlorothalonil (2,4,5,6-tetrachloro-isophthalonitrile), TCMTB (2-thiocyanomethylthiobenzothiazole), diuron (3-(3,4-dichlorophenyl)-1, 1-dimethylurea), TBT, 2-methylthio-4-tert-butylamino-6-amino-s-triazine (a degradation product of Irgarol 1051), 1-(3,4-dichlorophenyl) methylurea, and 1-(3,4-dichlorophenyl) urea. The latter two compounds are degradation products of diuron. All selected chemicals were of the highest purity available from Ciba-Geigy (Barcelona, Spain), Rhom \& Hass (Philadelphia, USA), Chemservice (West Chester, USA) and Riedel-de-Haën (Seelze, Germany). The selected compounds represented a broad range of chemical structures and different modes of action (Table 1).

Stock solutions of the compounds and the mixtures were prepared in distilled water for the Vibrio fischeri bioassay and in the culture media for the Selenastrum capricornotum and Daphnia magna bioassays. Mixtures of antifoulants were produced by combining various stock solutions of pure components in a ratio of $1: 1$ by volume. When using mixtures, the concentration of the toxicant was defined as the sum of concentrations of all the antifoulants in solution. When a compound had a low solubility in water, $0.5 \%$ dimethyl sulfoxide was used to dissolve it. All mixtures of the antifouling agents contained Irgarol 1051, a compound that is commonly used and detected in marinas of several European countries [6-9]. Dimethyl sulfoxide 
Table 1

Antifouling agents studied and their characteristics.

\begin{tabular}{llll}
\hline Antifouling agent & Chemical class & Biocidal application & Mode of action \\
\hline Chlorothalonil & Organochlorine & Fungicide & Inhibitor of mitochondrial electron transport \\
Dichlofluanid & Organochlorine & Fungicide & Carcinogenic/mutagenic \\
Diuron & Phenylureas & Herbicide & Photosynthesis inhibitor \\
Irgarol 1051 & $s$-Triazines & Herbicide & PS II inhibitor \\
Sea nine 211 & Isothiazolone & Herbicide & PS II inhibitor \\
TCMTB & Benzothiazol & Fungicide & Inhibitor of mitochondrial electron transport \\
TBT & Organotin & Herbicide & PS II inhibitor \\
\hline
\end{tabular}

(DMSO, 97\%) was purchased from Merck (Dusseldorf, Germany). Control experiments carried out with equivalent volumes of DMSO exhibited no observable effect on the studied biological species.

\subsection{Ecotoxicity tests}

Toxicities were evaluated using bioassays based on a luminescent bacterium ( $V$. fischeri), a microalga (S. capricornotum), and a microscopic crustacean (D. magna).

The bacterial assay used the commercially available BioTox test system (Bio-Orbit Oy, Turku, Finland). The $\mathrm{EC}_{50}$ values were determined for 5, 15 and 30 min exposure of the bacterium to the toxicants. $V$. fischeri is a luminescent bacterium. The metabolic pathway of light emission from the bacterium is intrinsically linked to cellular respiration and any disruption of normal cellular metabolism causes a decrease in light emission. The toxicity end-point $\left(\mathrm{EC}_{50}\right)$ was determined as the concentration of a test sample that caused a 50\% reduction in light output. The bioluminescence assay was carried out in accordance with the ISO 11348 protocol [16]. The light emission was measured with a photomultiplier with the samples held at a constant temperature of $15^{\circ} \mathrm{C}$.

The D. magna bioassay used a commercially available text kit (Daphtoxkit; Creasel, Belgium). The assay was carried out in accordance with the conditions prescribed by OECD Guideline 202 and the ISO 6341 protocol [17]. Acute toxicity was assessed by noting the effects of the test compounds on the motility of D. magna. The daphnids were used within $24 \mathrm{~h}$ of hatching from dormant eggs (ephippia). The tests were conducted in the dark at $20 \pm 1^{\circ} \mathrm{C}$. The neonates were considered immobile, if after 24 or
$48 \mathrm{~h}$ of incubation with the toxicant they remained settled at the bottom of the test container and did not resume swimming within the $15 \mathrm{~s}$ observation period. The toxicity end-point $\left(\mathrm{EC}_{50}\right)$ was determined as the concentration of the toxicant required to immobilize $50 \%$ of the daphnids after 24 and $48 \mathrm{~h}$ exposure.

The algal growth inhibition test was performed using the freshwater green alga $S$. capricornotum in accordance with the OECD Guideline 201 [18]. The commercially available Algaltoxkit (Creasel, Belgium) system was used. The algal cells were cultured in test tubes using the medium provided with the test kit. The initial number of algal cells was adjusted to $10^{6}$ cells $/ \mathrm{ml}$ and the test tubes were incubated at $25^{\circ} \mathrm{C}$ for 3 days under continuous illumination. Except for the controls, the test tube contained the test toxicant and the alga in the culture medium. Inhibition of the algal growth relative to controls was determined by measurements of optical density in a spectrophotometer at a wavelength of $670 \mathrm{~nm}$. The $72 \mathrm{~h} \mathrm{EC}_{50}$ value in this test was calculated as the concentration of the test substance which caused a 50\% reduction in growth relative to the control.

The acute toxicity response obtained in these bioassays was plotted against the toxicants' concentrations to obtain the dose-response curve. The linear portions of the curves were used to estimate the toxicity endpoints, $\mathrm{EC}_{50}$ and the lowest observable effect concentration (LOEC). LOEC represents the initial toxicity threshold of a chemical. The sensitivity of the bioassays was evaluated by comparing the LOEC values. The reproducibility of bioassay responses was evaluated by five replicates of the $\mathrm{EC}_{50}$ and LOEC measurements for the $V$. fischeri and $S$. capricornotum 
assays; six replicates were used for the D. magna assay.

\section{Results and discussion}

Toxic effects of the antifoulants were evaluated using bioassay species representing different trophic levels in the aquatic ecosystem. The assays used the bacterium $V$. fischeri, the microalga $S$. capricornotum and the crustacean D. magna. Zooplankton (in particular the Daphnids) are frequently used in ecotoxicological tests because they are highly sensitive to low doses of toxic chemicals. Also, zooplanktons occupy a central position in the lentic food chain [19].

\subsection{Single substance toxicities}

The toxicities ( $\mathrm{EC}_{50}$ values) of the compounds tested are reported in Table 2, for the three bioassays and the various periods of incubation. The $\mathrm{EC}_{50}$ values of test chemicals for the microalga $S$. capricornotum were lower than the $\mathrm{EC}_{50}$ values for the bacterium and the crustacean, suggesting that the photosynthetic species (i.e. phytoplankton) are generally more sensitive to the tested antifoulants than are the other organisms.

Although, all the test chemicals were substantially more toxic to the alga, the toxicity of most chemicals was sufficiently broad to affect both the bacterium and the crustacean. Obviously, the chemicals tested have abroad toxic impact on a great range of aquatic species. Only Irgarol 1051 and diuron were relatively nontoxic $\left(\mathrm{EC}_{50} \geq 7 \mathrm{mg} / \mathrm{l}\right)$ to the nonphotosynthetic organisms (i.e. the bacterium and the crustacean) but retained high toxicity toward the alga.

The toxicity of tested chemicals toward the microalga was as follows (in descending order of toxicities): TBT $=$ Kathon 5287 (Sea nine 211) > chlorothalonil $>$ Irgarol $1051>$ diuron $>$ dichlo fluanid $>$ TCMTB. For D. magna ( $48 \mathrm{~h}$ incubation), the descending order of toxicities of the various compounds was TBT $>$ Kathon $5287>$ chlorothalonil $>$ TCMTB > dichlofluanid > Irgarol $1051>$ diuron. For $V$. fischeri (30 min incubation), the descending toxicity series was determined to be: Kathon $5287>$ TBT $>$ TCMTB $>$ dichlofluanid $>$ Irgarol $1051>$ chlorothalonil.
TBT and Kathon 5287 were the most toxic to the organisms selected. The toxicity of these compounds was clearly nonspecific, as they had similar effects on all the organisms tested. In view of this, the replacement of TBT by Kathon 5287 does not offer any clear advantage in terms of reducing acute toxicity in aquatic systems. However, the half-life of Kathon 5287 is much lower [14] than TBT's and this reduces the bioaccumulation potential of Kathon 5287. Also, in comparison with TBT the literature data [14] suggest a much lower chronic or reproductive toxicity of Kathon 5287 toward certain marine mammals. While the bioaccumulation potential and chronic toxicities are important, the high acute toxicity of Kathon 5287 relative to TBT requires consideration in establishing ecotoxicological criteria for water quality.

Chlorothalonil, dichlofluanid and TCMTB, which are commonly qualified as fungicides, showed toxic effects on nontarget organisms. Chlorothalonil was more toxic to the microalga $\left(\mathrm{EC}_{50} \geq 0.0068 \mathrm{mg} / \mathrm{l}\right)$ than some of the specific inhibitors of photosynthesis (e.g. Irgarol 1051, diuron). Dichlofluanid and TCMTB were quite toxic to the bacterium $\left(\mathrm{EC}_{50} \geq 0.0068\right.$ and $0.039 \mathrm{mg} / \mathrm{l}$, respectively). Only chlorothalonil was relatively nontoxic to the bacterium $\left(\mathrm{EC}_{50} \geq 42.4 \mathrm{mg} / \mathrm{l}\right)$.

As a consequence of the natural degradation processes in the aquatic environment, the antifoulants produce degradation products that can be more or less toxic than the parent compound. Obviously, therefore, a complete assessment of a compound's toxicity needs to address the toxicity of its degradation products. Information on the persistence of Irgarol 1051 and diuron in the aquatic environment is limited. Studies assessing photodegradation demonstrate that sunlight degrades more than $80 \%$ of Irgarol in water over 15 weeks [20]. Biodegradation, photodegradation and chemical hydrolysis of Irgarol 1051 all result in $n$-dealkylation to yield 2-methylthio-4-tert-butylamino-6-amino-s-triazine as the principal degradation product [21]. For diuron, the estimated half-life in the environment is 90 days [22].

The toxicity values of the degradation products of Irgarol 1051 and diuron are reported in Table 3. The comparison of $\mathrm{EC}_{50}$ values of Irgarol 1051 (Table 2) and its degradation product indicates that the target parent compound is 2.5 -fold more toxic than its major degradation product, when tested with D. magna. However, the toxicities of the degradation product of 
Table 2

Acute toxicity ( $\mathrm{EC}_{50}$ values) of individual antifouling agents

\begin{tabular}{|c|c|c|c|c|c|c|}
\hline \multirow[t]{3}{*}{ Antifouling agent } & \multicolumn{6}{|l|}{$\mathrm{EC}_{50}(\mathrm{mg} / \mathrm{l})$} \\
\hline & \multicolumn{2}{|l|}{ V. fischeri } & \multicolumn{2}{|l|}{ S. capricornotum } & \multicolumn{2}{|l|}{ D. magna } \\
\hline & $5 \min ^{\mathrm{a}}$ & $15 \min ^{\mathrm{a}}$ & $30 \mathrm{~h}^{\mathrm{a}}$ & $72 \mathrm{~h}^{\mathrm{a}}$ & $24 \mathrm{~h}^{\mathrm{a}}$ & $48 \mathrm{~h}^{\mathrm{a}}$ \\
\hline Chlorothalonil & - & - & $42.4 \pm 3.27$ & $0.0068 \pm 0.001$ & $0.07 \pm 0.0139$ & $0.028 \pm 0.005$ \\
\hline Sea nine 211 & $0.036 \pm 0.0047$ & $0.012 \pm 0.0013$ & $0.003 \pm 0.0003$ & $0.003 \pm 0.0004$ & $0.008 \pm 0.0015$ & $0.004 \pm 0.0007$ \\
\hline Irgarol 1051 & - & $50.8 \pm 7.8$ & $15.5 \pm 2.7$ & $0.0108 \pm 0.0017$ & $10 \pm 1.8$ & $7.3 \pm 1.24$ \\
\hline Diuron & - & - & - & $0.045 \pm 0.0079$ & - & $8.6 \pm 1.3$ \\
\hline Dichlofluanid & $0.113 \pm 0.018$ & $0.087 \pm 0.0157$ & $0.064 \pm 0.0118$ & $0.133 \pm 0.021$ & $1.3 \pm 0.17$ & $1.05 \pm 1.33$ \\
\hline TCMTB & $0.12 \pm 0.013$ & $0.058 \pm 0.012$ & $0.039 \pm 0.0078$ & $0.433 \pm 0.068$ & $0.049 \pm 0.0067$ & $0.046 \pm 0.0068$ \\
\hline TBT & $0.022 \pm 0.004$ & $0.011 \pm 0.003$ & $0.007 \pm 0.0012$ & $0.003 \pm 0.0004$ & $1 \times 10^{-9} \pm 1.2 \times 10^{-20}$ & $1 \times 10^{-9} \pm 1.1 \times 10^{-10}$ \\
\hline
\end{tabular}

Data are expressed as mean \pm S.D.

${ }^{\mathrm{a}}$ Exposure. 
Table 3

$\mathrm{EC}_{50}$ values for degradation product of Irgarol 1051 and diuron

\begin{tabular}{|c|c|c|c|c|c|c|}
\hline \multirow[t]{3}{*}{ Degradation product } & \multicolumn{6}{|l|}{$\mathrm{EC}_{50}(\mathrm{mg} / \mathrm{l})$} \\
\hline & \multicolumn{2}{|l|}{ V. fischeri } & \multicolumn{2}{|c|}{ S. capricornotum } & \multicolumn{2}{|l|}{ D. magna } \\
\hline & $5 \min ^{\mathrm{a}}$ & $15 \min ^{\mathrm{a}}$ & $30 \mathrm{~h}^{\mathrm{a}}$ & $72 \mathrm{~h}^{\mathrm{a}}$ & $24 \mathrm{~h}^{\mathrm{a}}$ & $48 \mathrm{~h}^{\mathrm{a}}$ \\
\hline 1-(3,4-Dichlorophenyl) methylurea & $8.9 \pm 1.79$ & $5.6 \pm 0.88$ & $3.9 \pm 0.65$ & $0.058 \pm 0.01$ & $0.4 \pm 0.09$ & $0.04 \pm 0.008$ \\
\hline 1-(3,4-Dichlorophenyl) urea & $11.1 \pm 1.7$ & $10.3 \pm 1.66$ & $9.6 \pm 1.46$ & $0.07 \pm 0.01$ & $14.9 \pm 2.5$ & $14.9 \pm 2.23$ \\
\hline 2-Methylthio-4-tert-butylamino-6-amino-s-triazine & $7.3 \pm 1.4$ & $6.5 \pm 0.89$ & $4.7 \pm 0.93$ & $0.018 \pm 0.003$ & $18.9 \pm 3.54$ & $18.9 \pm 3.50$ \\
\hline
\end{tabular}

Data are expressed as mean \pm S.D.

${ }^{\mathrm{a}}$ Exposure.

Irgarol 1051 and the parent compound were similar toward S. capricornotum. The degradation product was more bactericidal than Irgarol 1051.

The $48 \mathrm{~h} \mathrm{EC}_{50}$ values (D. magna assay) of Irgarol and its degradation product have been reported as 8.3 and $11 \mathrm{mg} / \mathrm{l}$, respectively. Our data (Table 2) are consistent with the reported values. The $72 \mathrm{~h}$ $\mathrm{EC}_{50}$ values for Irgarol and its degradation product were 1.6 and $19 \mu \mathrm{g} / \mathrm{l}$ when measured with $S$. capricornotum [16]. The $72 \mathrm{~h} \mathrm{EC}_{50}$ value reported for 2-methylthio-4-tert-butylamino-6-amino-s-triazine was very similar to the $72 \mathrm{~h} \mathrm{EC}_{50}$ values obtained in our work $(18 \mu \mathrm{g} / \mathrm{l})$; however, the earlier reported $72 \mathrm{~h} \mathrm{EC} 50$ value of Irgarol 1051 [16] was 6.75 times lower than observed by us. Toxicity values for diuron and its degradation products were comparable when tested with the microalga. The $\mathrm{EC}_{50}$ values of diuron and its degradation product (1-(3,4-dichlorophenyl) methyl urea) indicate that the degradation product is 215 times more toxic to D. magna than is the parent compound.

These results suggest that the herbicidal action of the parent compounds and their degradation products tested are similar, but the degradation products have a higher nonspecific toxic action than the parent compound when tested with the bacterial assay. Significantly, two of the degradation products (1-(3,4-dichlorophenyl) urea and 2-methylthio-4-tert-butylamino-6-amino-s-triazine) were less toxic to D. magna than the parent antifouling agents.

The LOEC values of the compounds tested are reported in Table 4. Sensitivity of these bioassays was evaluated using the LOEC values. LOEC values were lower than $\mathrm{EC}_{50}$ values by factors of 1.3-3.5 for the bacterium, by factors of 2.6-30 for the microalga and by factors of 1.7-4 for the crustacean.
The adverse toxic effects occurred at different concentrations of a compound when tested using the different bioassays. For example, for TBT the adverse effects on D. magna, S. capricornotum and V. fischeri were seen at concentrations of $0.8 \mathrm{ppt}, 0.1$ and 2 ppb, respectively. For Kathon 5287, the adverse effects were seen at the following concentrations: $4 \mathrm{ppb}$ with $D$. magna, $0.3 \mathrm{ppb}$ with $S$. capricornotum and $1.5 \mathrm{ppb}$ with V. fischeri. Most antifoulants had LOEC values of ppb levels. Relatively high LOEC values were observed for Irgarol 1051 and diuron tested on the bacterium (LOEC $=7.6$ and $23 \mathrm{mg} / \mathrm{l}$, respectively). Irgarol 1051 and diuron gave high LOEC values (LOEC $=2.4$ and $3.5 \mathrm{mg} / \mathrm{l}$, respectively) with the crustacean test also. Chlorothalonil had a relatively low toxicity toward the bacterium ( $\mathrm{LOEC}=30 \mathrm{mg} / \mathrm{l}$ ).

Average reproducibility of the $\mathrm{EC}_{50}$ and LOEC measurements was 27,24 and $28 \%$, respectively, in the BioTox, the Algaltoxkit and the Daphtoxkit bioassays. Although, these levels of variability seem high in comparison with the conventional analytical techniques, the reproducibility values are reasonably good considering the inherent variability of biological systems. The BioTox reproducibility values reported by others have been between 10 and $20 \%$ for pure compounds [23,24]. In our case, the $\mathrm{EC}_{50}$ reproducibility in Tables 2 and 3 for pure compounds is within $\pm 20 \%$ for $92 \%$ of the measurements with the BioTox system. Only two sets of measurements had reproducibility values between 20 and $28 \%$. Not much data has been reported on mixture toxicity measured with any of the bioassays. Little has been published on the reproducibility of the Algatoxkit used. The Daphtoxkit bioassay is known to be significantly less reproducible (although highly sensitive) than the BioTox, as affirmed in this work and earlier studies [15]. 
Table 4

LOEC values of individual antifouling agents

\begin{tabular}{|c|c|c|c|c|c|c|}
\hline \multirow[t]{3}{*}{ Antifouling agent } & \multicolumn{6}{|l|}{ LOEC (mg/l) } \\
\hline & \multicolumn{2}{|l|}{ V. fischeri } & \multicolumn{2}{|l|}{ S. capricornotum } & \multicolumn{2}{|l|}{ D. magna } \\
\hline & $5 \min ^{\mathrm{a}}$ & $15 \min ^{\mathrm{a}}$ & $30 \mathrm{~h}^{\mathrm{a}}$ & $72 \mathrm{~h}^{\mathrm{a}}$ & $24 \mathrm{~h}^{\mathrm{a}}$ & $48 \mathrm{~h}^{\mathrm{a}}$ \\
\hline Chlorothalonil & - & - & $30 \pm 5.36$ & $0.001 \pm 0.00014$ & $0.016 \pm 0.0025$ & $0.014 \pm 0.0018$ \\
\hline Sea nine 211 & $0.0016 \pm 0.0002$ & $0.0017 \pm 0.00026$ & $0.0015 \pm 0.00028$ & $0.0003 \pm 0.0005$ & $0.004 \pm 0.00068$ & $0.001 \pm 0.00018$ \\
\hline Irgarol 1051 & - & $10 \pm 1.9$ & $7.6 \pm 1.4$ & $0.005 \pm 0.0009$ & $5 \pm 0.95$ & $2.4 \pm 0.33$ \\
\hline Diuron & - & - & $23 \pm 4.25$ & $0.015 \pm 0.0026$ & - & $3.5 \pm 0.69$ \\
\hline Dichlofluanid & $0.028 \pm 0.005$ & $0.027 \pm 0.0047$ & $0.029 \pm 0.006$ & $0.05 \pm 0.0087$ & $0.8 \pm 0.121$ & $0.62 \pm 0.10$ \\
\hline ТСМТВ & $0.029 \pm 0.0047$ & $0.03 \pm 0.0042$ & $0.029 \pm 0.0053$ & $0.15 \pm 0.035$ & $0.021 \pm 0.0046$ & $0.021 \pm 0.0048$ \\
\hline TBT & $0.003 \pm 0.00041$ & $0.002 \pm 0.00029$ & $0.002 \pm 0.0003$ & $0.0001 \pm 0.00002$ & $0.8 \times 10^{-9} \pm 1.2 \times 10^{-10}$ & $0.8 \times 10^{-9} \pm 1.2 \times 10^{-10}$ \\
\hline
\end{tabular}

Data are expressed as mean \pm S.D.

${ }^{a}$ Exposure. 
Table 5

Acute toxicity of mixed antifouling agents ${ }^{\mathrm{a}}$

\begin{tabular}{|c|c|c|c|c|c|c|}
\hline \multirow[t]{3}{*}{ Mixtures of antifouling agents } & \multicolumn{6}{|l|}{$\mathrm{EC}_{50}(\mathrm{mg} / \mathrm{l})$} \\
\hline & \multicolumn{2}{|l|}{ V. fischeri } & \multicolumn{2}{|l|}{ S. capricornotum } & \multicolumn{2}{|l|}{ D. magna } \\
\hline & $5 \min ^{\mathrm{b}}$ & $15 \min ^{\mathrm{b}}$ & $30 \mathrm{~h}^{\mathrm{b}}$ & $72 \mathrm{~h}^{\mathrm{b}}$ & $24 \mathrm{~h}^{\mathrm{b}}$ & $48 \mathrm{~h}^{\mathrm{b}}$ \\
\hline Irgarol 1051-diuron & $20.15 \pm 4.32$ & $11.95 \pm 2.12$ & $6.9 \pm 1.26$ & $0.006 \pm 0.0012$ & $0.304 \pm 0.066$ & $0.271 \pm 0.053$ \\
\hline Irgarol 1051-Sea nine 211 & $0.58 \pm 0.10$ & $0.37 \pm 0.061$ & $0.27 \pm 0.064$ & $0.006 \pm 0.0012$ & $0.052 \pm 1$ & $0.018 \pm 0.003$ \\
\hline Irgarol 1051-chlorthalonil & - & $9.5 \pm 1.86$ & $3.7 \pm 0.76$ & $0.003 \pm 0.0005$ & $0.443 \pm 0.095$ & $0.369 \pm 0.069$ \\
\hline Irgarol 1051-dichlofluanid & $0.527 \pm 0.1$ & $0.335 \pm 0.07$ & $0.212 \pm 0.048$ & $0.025 \pm 0.0055$ & $0.824 \pm 0.14$ & $0.654 \pm 0.107$ \\
\hline Irgarol 1051-TCMTB & $0.038 \pm 0.006$ & $0.014 \pm 0.003$ & $0.006 \pm 0.0008$ & $0.01 \pm 0.002$ & $0.021 \pm 0.004$ & $0.01 \pm 0.002$ \\
\hline $\begin{array}{l}\text { Irgarol 1051-diuron- } \\
\text { Sea nine } 211\end{array}$ & $2.7 \pm 0.45$ & $2 \pm 0.38$ & $1.8 \pm 0.42$ & $0.011 \pm 0.0047$ & $0.05 \pm 0.0098$ & $0.039 \pm 0.007$ \\
\hline $\begin{array}{l}\text { Irgarol 1051-TCMTB- } \\
\text { dichlofluanid }\end{array}$ & $0.088 \pm 0.016$ & $0.051 \pm 0.010$ & $0.048 \pm 0.009$ & $0.01 \pm 0.0021$ & $0.055 \pm 0.0095$ & $0.04 \pm 0.008$ \\
\hline $\begin{array}{l}\text { Irgarol 1051-TCMTB- } \\
\quad \text { dichlofluanid-Sea nine } 211\end{array}$ & $0.089 \pm 0.018$ & $0.046 \pm 0.008$ & $0.044 \pm 0.008$ & $0.104 \pm 0.042$ & $0.046 \pm 0.0088$ & $0.032 \pm 0.006$ \\
\hline
\end{tabular}

Data are expressed as mean \pm S.D.

${ }^{\mathrm{a}} \mathrm{EC}_{50}$ values of binary, ternary and quaternary mixtures are shown.

${ }^{\mathrm{b}}$ Exposure.

A published summary of reproducibly from several intra- and inter-laboratory studies reported an average reproducibility of $38.8 \%$ for the bioassays based on the most common invertebrate and fish test species [25]. Our values are consistent with these norms.

\subsection{Mixture toxicity}

The toxicity data for mixtures of antifoulants are shown in Table 5. The results reveal that the interactivity of chemicals in producing a toxic response needs to be considered in assessing the impact of toxicants on the aquatic environment. This is necessary because waterbodies are almost always contaminated with multiple toxicants. The methods used to relate the individual component toxicity to the expected toxicity of the mixture have been discussed in the literature [26]. Concentration addition has gained some acceptance as having a reasonable pharmacological basis. According to this model of a mixture's toxicity, the toxicities of individual components are additive if the substances act on common active sites of metabolic enzymes and if a constituent chemical acts as a diluant for the other components [27,28]. In this situation, the toxic effect of any component can be replaced with an equieffective amount of another chemical. Following this model, the concentration of each toxicant is expressed as a fraction of its $\mathrm{EC}_{50}$ (toxic unit, TU). In the case of concentration addition, the 50\% response of a mixture of chemicals is obtained when the sum of TUs $\left(\sum \mathrm{TU}\right)$ of all constituents equals unity. In contrast, when the sum of TUs exceeds unity, the combined effect of toxicants is more than additive (i.e. a synergistic response). Similarly, when the sum of TUs is $<1$ then the toxic response is less than additive, i.e. the toxicants act antagonistically [26,29].

We used mixtures of the biocides at equal molar concentrations of toxicants, to obtain an equal theoretical probability of competition of the various biocides for the binding sites of target molecules. A comparison of the $\mathrm{EC}_{50}$ values of Irgarol 1051 and its mixtures indicates an enhancement of toxicity in $79 \%$ of the cases when the antifoulants are combined. Using the bacterial assay, the $\mathrm{EC}_{50}$ value of Irgarol 1051 was 2.2-2583 times greater than the $\mathrm{EC}_{50}$ values of its binary mixtures. Lower toxicity enhancements were seen for the mixtures, using the microalga and the crustacean assays. A binary mixture of Irgarol 1051-TCMTB was more toxic than Irgarol 1051 by a factor of 2500, using the $V$. fischeri test but only 730 times more toxic when tested with $D$. magna assay system.

The ternary mixtures had higher $\mathrm{EC}_{50}$ values with bacterial and daphnid assays when compared to the $\mathrm{EC}_{50}$ value of Irgarol 1051. Mixtures of Irgarol 1051-dichlofluanid-TCMTB and Irgarol 1051-diuron-Kathon 5287 were more toxic 
Table 6

Toxicity of mixtures relative to pure-component toxicity

\begin{tabular}{|c|c|c|c|}
\hline \multirow[t]{2}{*}{ Mixtures of antifouling agents } & \multicolumn{3}{|c|}{ Mixture toxicity } \\
\hline & V. fischeri & S. capricornotum & D. magna \\
\hline Irgarol 1051-diuron & Synergistic $^{\mathrm{a}}$ & Synergistic $^{\mathrm{a}}$ & Synergistic $^{\mathrm{b}}$ \\
\hline Irgarol 1051-Sea nine 211 & Antagonistic $^{\mathrm{b}}$ & Additive & Additive \\
\hline Irgarol 1051-chlorthalonil & Synergistic $^{\mathrm{a}}$ & Synergistic $^{\mathrm{a}}$ & Antagonistic ${ }^{\mathrm{a}}$ \\
\hline Irgarol 1051-dichlofluanid & Additive & Additive & Synergistic ${ }^{\mathrm{a}}$ \\
\hline Irgarol 1051-TCMTB & Synergistic ${ }^{c}$ & Synergistic ${ }^{a}$ & Synergistic ${ }^{c}$ \\
\hline Irgarol 1051-diuron-Sea nine 211 & Antagonistic ${ }^{c}$ & Additive & Additive \\
\hline Irgarol 1051-TCMTB-dichlofluanid & Additive & Synergistic $^{\mathrm{a}}$ & Synergistic $^{\mathrm{a}}$ \\
\hline Irgarol 1051-TCMTB-dichlofluanid-Sea nine 211 & Antagonistic ${ }^{\mathrm{a}}$ & Antagonistic ${ }^{b}$ & Additive \\
\hline
\end{tabular}

a Two to 10-fold increase (synergistic) or decrease (antagonistic) in toxicity.

${ }^{\mathrm{b}}$ Ten to 50-fold increase (synergistic) or decrease (antagonistic) in toxicity.

${ }^{\mathrm{c}}$ More than 100-fold increase (synergistic) or decrease (antagonistic) in toxicity.

than Irgarol 1051 by factors of $8.6-322.3$ ( $\mathrm{V}$. fischeri assay). The quaternary mixture Irgarol 1051-dichlofluanid-TCMTB-Kathon 5287 was more toxic than Irgarol 1051 by factors of 352.3 (V. fischeri assay) and 228.1 (D. magna test). The quaternary mixture was less toxic than Irgarol 1051 by a factor of 9.6 when tested with the microalga. Clearly, when considering the potential environmental impact, evaluating toxicities of mixtures is as important as evaluation of single-compound toxicity.

Based on experimental $\mathrm{EC}_{50}$ values of constituent components, the expected toxicities of the mixtures can be calculated by summing the concentrations. A comparison of the calculated toxicity with the experimentally observed toxicity of the mixture determines if the toxic response is additive, synergistic, or antagonistic. Table 6 documents the observed effects for binary, ternary and quaternary mixtures. For $33 \%$ of the mixtures, the results were consistent with the concentration addition model; $21 \%$ of the mixtures were less toxic than expected from this model (antagonistic effect) and synergistic effects were seen for a majority $(46 \%)$ of the mixtures. In view of these observations, a consideration of synergistic interactions is important in establishing the acceptable contamination limits for aquatic ecosystems.

\section{Conclusions}

Various bioassays were used to assess the individual compound toxicity and the mixture toxicity of some commonly used antifouling agents and the degradation products of these agents. The selected bioassays spanned a range of metabolically diverse organisms of the aquatic environment. Individually, most of the single herbicidal agents were also toxic to the nonphotosynthetic organisms (V. fischeri and D. magna). Also, the degradation products of the selected herbicidal agents proved to possess nonspecific toxic activity. A synergistic toxic response was seen for a clear majority of the cases, suggesting that a consideration of individual component toxicity alone is not sufficient for determining the environmental impacts of toxicants. Contamination with mixtures of the antifouling agents studied could affect a primary producer community in aquatic ecosystems at concentration levels as low as $6 \mu \mathrm{g} / \mathrm{l}$.

\section{References}

[1] S.M. Evans, A.C. Birchenough, M.S. Brancato, Marine Pollut. Bull. 40 (2000) 204-211.

[2] A.H. Jacobson, G.L. Willingham, Sci. Total Environ. 258 (2000) 103-110.

[3] B. Dahl, H. Blanck, Marine Pollut. Bull. 32 (1996) 342-350.

[4] P.Y. Caux, R.A. Kent, G.T. Fan, G.L. Srephenson, Crit. Rev. Environ. Sci. Technol. 26 (1996) 45-93.

[5] W. Ernst, K. Doe, P. Jonah, J. Young, G. Julien, P. Hennigar, Arch. Environ. Contam. Toxicol. 21 (1991) 1.

[6] S. Tóth, K. Becker-van-Slooten, L. Spack, L.F. De Alencastro, J. Tarradellas, Bull. Environ. Contam. Toxicol. 57 (1996) 426-433.

[7] K. Thomas, J. Chromatogr. A 825 (1998) 29-35.

[8] K. Martinez, I. Ferrer, D. Barcelo, J. Chromatogr. A 879 (2000) 27-37. 
[9] A. Agüera, L. Piedra, M.D. Hernando, A.R. Fernández-Alba, J. Chromatogr. A 889 (2000) 261-269.

[10] L.W. Hall, J.M. Giddings, K.R. Solomon, R. Balcomb, Crit. Rev. Toxicol. 29 (1999) 367-437.

[11] L. Piedra, A. Tejedor, M.D. Hernando, A. Agüera, D. Barceló, A.R. Fernández-Alba, Chromatographia 52 (2000) 631-638.

[12] R.J.C.A. Steen, P.E.G. Leonards, U.A.Th. Brinkman, W.P. Cofino, J. Chromatogr. A 766 (1997) 153-158.

[13] I. Ferrer, B. Ballesteros, M.P. Marco, D. Barceló, Env. Sci. Technol. 31 (1997) 3530-3535.

[14] K.V. Thomas, J. Chromatogr. A 833 (1999) 105-109.

[15] A.R. Fernández-Alba, M.D. Hernando, G.D. López, Y. Chisti, Anal. Chim. Acta 426 (2001) 289-301.

[16] ISO 11348-2, Water quality-determination of the inhibitory effect of water samples on the light emission of Vibrio fischeri (luminescent bacteria test), draft, September 1994, Geneva (revised).

[17] Daphnia sp., Acute Immobilisation Test, OECD Guidelines for the Testing of Chemicals, Vol. 1, no. 201, 1995, pp. 1-15.

[18] Alga, Growth Inhibition Test, OECD Guidelines for the Testing of Chemicals, Vol. 1, no. 202, 1995, pp. 1-14.

[19] T. Hanazato, Environ. Pollut. 112 (2001) 1-10.

[20] H. Okamura, L. Aoyama, D. Liu, J. Maguire, C.G. Pacepavicus, Y.L. Lau, J. Environ. Sci. Health Part B.
Pesticide Food Contaminants and Agricultural Wastes 34 (1999) 225-238.

[21] D. Liu, G.J. Pacepavicus, R.J. Maguire, Y.L. Lau, H. Okamura, I. Aoyama, Water Res. 33 (1999) 2833-2843.

[22] D. Simon, S. Helliwell, K. Robards, Anal. Chim. Acta 360 (1998) 1-16.

[23] M.J. Ruiz, L. López-Jaramillo, M.J. Redondo, G. Font, Bull. Environ. Contam. Toxicol. 59 (1997) 619-625.

[24] Microbics Corporation. Microtox M500 Manual, A Toxicity Testing Handbook, Microbics Corporation, Carslbad, CA, USA, 1994.

[25] USEPA (United States Environmental Protection Agency), Technical Support Document for Water Quality-based Toxics Control, EPA/505/2-90-001, PB91-127415, 1991.

[26] M. Faust, R. Altenburger, W. Boedeker, L.H. Grimme, Sci. Total Environ., Supplement, 1993, pp. 941-952.

[27] R. Altenburger, T. Backhaus, W. Boedeker, M. Faust, M. Scholze, Environ. Toxicol. Chem. 19 (2000) 23412347.

[28] T. Backhaus, R. Altenburger, W. Boedeker, M. Faust, M. Scholze, L.H. Grimme, Environ. Toxicol. Chem. 19 (2000) 2348-2356.

[29] M. Faust, R. Altenburger, W. Boedeker, L.H. Grimme, Bull. Environ. Contam. Toxicol. 53 (1994) 134-141. 